\title{
Periodic breathing during sleep in patients affected by fibromyalgia syndrome
}

\author{
M. Sergi ${ }^{+}$, M. Rizzi ${ }^{+}$A. Braghiroli**, P. Sarzi Puttini*, M. Greco*, M. Cazzola*, A. Andreoli ${ }^{+}$
}

Periodic breathing during sleep in patients affected by fibromyalgia syndrome. M. Sergi, M. Rizzi, A. Braghiroli, P. Sarzi Puttini, M. Greco, M. Cazzola, A. Andreoli. (C)ERS Journals Ltd 1999.

ABSTRACT: Seventeen patients affected by fibromyalgia syndrome (FMS) (16 females and one male) and 17 matched healthy subjects underwent formal polysomnography, a sleep questionnaire and lung function tests.

FMS patients slept significantly less efficiently than the healthy controls $(p<0.01)$, had a higher proportion of stage 1 sleep (mean $\pm S D, 21 \pm 6 \%$ versus $11 \pm 4 \% ; p<0.001$ ), less slow wave sleep $(\mathbf{p}<0.01)$ and twice as many arousals per hour of sleep $(\mathbf{p}<0.001)$. The respiratory pattern of FMS patients showed a high occurrence of periodic breathing (PB) $(15 \pm 8 \%$ of total sleep time) in $15 / 17$ patients, versus $2 / 17$ control subjects. The short length of apnoeas and hypopnoeas did not affect the apnoea/ hypopnoea index $(5.1 \pm 3.5$ versus $3.2 \pm 1.6$; Ns), but FMS patients had a greater number of desaturations per hour of sleep $(8 \pm 5$ versus $3 \pm 3 ; p<0.01)$.

Pulmonary volumes did not differ between the two groups, but FMS patients had a lower transfer factor of the lung for carbon monoxide $(T \mathrm{~L}, \mathrm{CO}(5.8+1$ versus $7.7+1$ $\left.\mathrm{mmol} \cdot \mathrm{min}^{-1} \cdot \mathrm{kPa}^{-1} ; \mathrm{p}=0.001\right)$. PB occurrence correlated with $T \mathrm{~L}, \mathrm{CO}(\mathrm{r}=-\mathbf{0 . 6 2} ; \mathrm{p}=0.01)$, number of desaturations $(\mathrm{r}=0.76, \mathrm{p}=\mathbf{0 . 0 0 1})$ and carbon dioxide tension in arterial blood $\left(\mathrm{Pa}_{\mathrm{a}} \mathrm{CO}_{2}\right)(\mathrm{r}=-\mathbf{0 . 5 0} ; \mathrm{p}=\mathbf{0 . 0 5})$. Stepwise multiple linear regression analysis showed desaturation frequency $(\mathrm{p}=0.0001)$ and $T \mathrm{~L}, \mathrm{CO}(\mathrm{p}=0.029)$ to be the best predictors of $\mathrm{PB}$ percentage $\left(R^{2} 0.73 ; p=0.0001\right)$.

Patients complaining of daytime hypersomnolence had a higher number of tender points, about twice as many arousals per hour and a lower sleep efficiency than patients who did not report this symptom. $T \mathrm{~L}, \mathrm{CO}$ was more impaired and the occurrence of PB was higher.

The occurrence of periodic breathing in fibromyalgia syndrome patients, which was previously unreported, and is shown to be linked to a reduction of transfer factor of the lung for carbon monoxide could play a major role in the symptoms of poor sleep of these patients.

Eur Respir J 1999; 14: 203-208.

Fibromyalgia syndrome (FMS) is a common rheumatic disorder characterized by generalized musculoskeletal pain and diffuse tenderness at discrete anatomic locations, termed tender points (TP) [1]. Eighty to $90 \%$ of patients are females, and the peak age is 30-50 yrs.

The criteria used for diagnosis of FMS were published by the American College of Rheumatology in 1990 [2]. The pain is widespread, lasting for at least three months, bilateral, above and below the waist axial, and in at least 11 out of 18 specified TP. Synovitis or myositis are absent. Other characteristics of the syndrome, often present, but not essential for the diagnosis, are; chronic fatigue, migraine, irritable bowel syndrome, headaches, paraesthesias, Raynaud's like symptoms, depression, anxiety and nonrestorative and/or disturbed sleep [3]. The reported complaint of poor sleep is so common in FMS patients that in some case series its prevalence is $75-80 \%[4,5]$. The observation that a neurasthenic musculoskeletal pain syndrome can be elicited in normal volunteers undergoing a selective deep nonrapid eye movement (NREM) sleep deprivation [6] seems to suggest that a vicious circle may be in operation, with pain impaired sleep leading to a worsening of the disease. An alpha intrusion on delta
${ }^{+}$Servizio di Fisiopatologia Respiratoria, * Servizio di Reumatologia, Azienda Ospedaliera - Polo Universitario L. Sacco, Milano, Italy. **Fondazione "S. Maugeri" IRCCS Div Pneumologia Centro Medico Veruno, Italy.

Correspondence: M. Sergi

Azienda Ospedalicra-Polo Universitario L. Sacco

Via G.B. Grassi 74

20157 Milano

Italy

Fax: 39023560042

Keywords: Fibromyalgia

periodic breathing

polysomnography

sleep

Received: June 301998

Accepted after revision March 151999 sleep was proposed by MoLDOFSKy et al in 1975 [7] as a marker of the sleep impairment typical of FMS patients, but this has not been confirmed by other studies [8, 9], while an association between alpha intrusion in NREM sleep and other FMS symptoms has been variously confirmed [10] and rejected [5] by different trials.

The hypothesis that other disorders causing sleep fragmentation, such as sleep apnoea syndrome [11], might be blamed for the nonrefreshing sleep symptoms reported by FMS patients was not confirmed by a controlled study [12].

Taking these contrasting results into consideration, the present study, compared sleep complaints, sleep architecture, number of arousals, alpha-delta activity occurrence and respiratory function in patients with FMS versus healthy control subjects.

\section{Materials and methods}

\section{Population}

Seventeen consecutive Caucasian patients (16 females) aged $($ mean $\pm \mathrm{SD}) \quad 51.2 \pm 8.9$ yrs with FMS, diagnosed 
according to the 1990 American College of Rheumatology Classification Criteria [2], were compared with 17 healthy subjects well matched in terms of age, sex, body mass index (BMI), and respiratory function (table 1).

Informed consent was obtained in all cases. The study was approved by the Hospital Medical Ethics Committee.

The clinical picture of patients was homogeneous, the mean disease duration was $4.7 \pm 2.5$ yrs and there were $13.8 \pm 2.1 \mathrm{TP}$ out of 18 possible (table 2 ).

The only psychotropic drugs used were benzodiazepines used as hypnoinducers by two patients and were withdrawn two weeks before the study to avoid a rebound effect or withdrawal symptoms.

Criteria for control subject selection included the absence of musculoskeletal pain, the absence of medical, neurological or psychiatric disorders and no heavy tobacco or alcohol consumption or drug abuse. None of the patients had signs of cardiac impairment.

A sleep questionnaire was administered to all subjects to evaluate sleep complaints and hypersomnolence [12].

\section{Recordings}

Polysomnography (PSG) was performed in the sleep laboratory, a sound attenuated room with temperature control, using a computer assisted device (Alice 3; Healthdyne, Marietta, OH, USA). The electroencephalogram (EEG), electro-oculogram (EOG), and submental electromyogram (Chin) were recorded with surface electrodes using standard techniques [13]. Airflow and ventilatory efforts were recorded respectively by naso-oral thermocouples and thoracic and abdominal belts with built-on piezo elec-

Table 1. - Anthropometric, clinical and pulmonary function data in patients affected by fibromyalgia syndrome (FMS) and in control subjects

\begin{tabular}{|c|c|c|c|}
\hline & FMS & $\begin{array}{l}\text { Control } \\
\text { subjects }\end{array}$ & p-value \\
\hline Subjects $n$ & 17 & 17 & \\
\hline Age yrs & $51.2 \pm 8.9$ & $51.4 \pm 10$ & NS \\
\hline Sex F/M & $16 / 1$ & $16 / 1$ & \\
\hline $\mathrm{BMI} \mathrm{kg} \cdot \mathrm{m}^{-2}$ & $25.8 \pm 3.7$ & $26.5 \pm 5.1$ & NS \\
\hline FVC L & $2.8 \pm 0.7$ & $2.9 \pm 0.8$ & NS \\
\hline FEV1 L & $2.5 \pm 0.6$ & $2.5 \pm 0.6$ & NS \\
\hline RV L & $1.6 \pm 0.6$ & $1.7 \pm 0.4$ & NS \\
\hline TLC L & $4.4 \pm 1.0$ & $4.6 \pm 0.8$ & NS \\
\hline $\begin{array}{l}\text { TL,COsb } \\
\mathrm{mmol} \cdot \mathrm{min}^{-1} \cdot \mathrm{kPa}^{-1}\end{array}$ & $5.8 \pm 1$ & $7.7 \pm 1$ & 0.001 \\
\hline $\begin{array}{l}\text { KCO } \\
\quad \mathrm{mmol} \cdot \mathrm{min}^{-1} \cdot \mathrm{kPa}^{-1} \cdot \mathrm{L}^{-1}\end{array}$ & $1.6 \pm 0.2$ & $1.8 \pm 0.1$ & 0.01 \\
\hline $\begin{array}{l}D \mathrm{M} \\
\quad \mathrm{mmol} \cdot \mathrm{min}^{-1} \cdot \mathrm{kPa}^{-1} \cdot \mathrm{L}^{-1}\end{array}$ & $9.9 \pm 1.3$ & $13.4 \pm 1.6$ & 0.001 \\
\hline VC L & $0.53 \pm 0.05$ & $0.56 \pm 0.07$ & NS \\
\hline$P \mathrm{a}, \mathrm{O}_{2} \mathrm{kPa}$ & $12.1 \pm 0.9$ & $12.4 \pm 0.5$ & NS \\
\hline$P \mathrm{a}, \mathrm{CO}_{2} \mathrm{kPa}$ & $4.9 \pm 0.5$ & $5.3 \pm 0.4$ & NS \\
\hline $\mathrm{Hb} g \cdot \mathrm{dL}^{-1}$ & $13.5 \pm 1$ & $13.4 \pm 0.9$ & NS \\
\hline
\end{tabular}

Data are number or mean \pm SD. BMI: body mass index; FVC: forced vital capacity; FEV1: forced expiratory volume in one second; RV: residual volume; TLC: total lung capacity; TL,COsb: transfer factor of the lung for carbon monoxide single breath holding method; KCO carbon monoxide transfer coefficient; $D M$ : diffusing capacity of the alveolar membrane; VC: volume of blood in the alveolar capillaries; $\mathrm{Pa}_{\mathrm{a}} \mathrm{O}_{2}$ : arterial blood oxygen partial pressure; $P \mathrm{a}, \mathrm{CO}_{2}$ : arterial blood carbon dioxide partial pressure; $\mathrm{Hb}$ : haemoglobin; F: female; M: male.
Table 2. - Symptoms, time from the first diagnosis and number of tender points in 17 fibromyalgia syndrome (FMS) patients and control subjects

\begin{tabular}{lccc}
\hline & \multicolumn{2}{c}{$\%$ patients } & \\
\cline { 2 - 3 } Symptoms & FMS & $\begin{array}{c}\text { Control } \\
\text { subjects }\end{array}$ & p-value \\
\hline Chronically poor sleep & 90 & 17 & 0.001 \\
Hypersomnolence & 59 & 11 & 0.01 \\
Wake-up unrefreshed & 82 & 17 & 0.001 \\
Nocturnal awakening & 100 & 11 & 0.001 \\
Fatigue & 90 & 29 & 0.001 \\
Headache & 82 & 11 & 0.001 \\
Bowel syndrome & 47 & 23 & NS \\
Habitual snorers & 53 & 29 & NS \\
Duration of FMS yrs & $4.7 \pm 2.5$ & & \\
Tender points n & $13.8 \pm 2.1$ & & \\
\hline
\end{tabular}

Data are per cent of patients or mean \pm SD.

trodes. Oxyhaemoglobin saturation was recorded by finger pulse oximetry (Pulsox-7; Minolta, Osaka, Japan). The transducers and lead wires allowed normal positional changes during sleep.

Bedtime and awakening time were at each subject's discretion; the polysomnography was terminated after final awakening. In order to avoid the first night effect each subject spent two nights in the sleep laboratory, only data recorded during the second night were evaluated.

\section{Interpretation of polysomnographic data}

Sleep and breathing variables were stored on an optical disk and then manually scored by two physicians, blinded, in $30 \mathrm{~s}$ epochs, according to standard criteria [13]. The correlation between sleep, breathing and body position was analysed automatically by the computer.

Apnoeas were defined as 10-s pauses in respiration. Hypopnoeas were defined as a decrement in airflow $\geq 50 \%$, associated with either an arousal at the end of the episode or a fall in arterial oxygen saturation $\left(\mathrm{Sa}_{\mathrm{a}} \mathrm{O}_{2}\right) \geq 4 \%$. The respiratory disturbance index (RDI) was defined as the average number of episodes of apnoea and hypopnoea per hour of sleep and the desaturation event frequency (DEF) was defined as the number of episodes of a fall $\geq 4 \%$ in oxyhaemoglobin saturation per hour of sleep. Periodic breathing (PB) was defined as a series of at least three successive cycles of waxing and waning in ventilation, with apnoeas or hypopnoeas. Arousals were scored according to the American Sleep Disorders Association (ASDA) criteria [14].

Alpha waves usually appear during wakefulness with eyes closed or in drowsy individuals, with a frequency of $7-11$ cycles $\cdot \mathrm{s}^{-1}$. Delta waves are the slow waves of deep sleep, with a frequency of $<2$ cycle $\cdot \mathrm{s}^{-1}$, and an amplitude $>75 \mu \mathrm{V}$. Alpha-delta intrusion was defined as the spontaneous occurrence of alpha waves in delta wave sleep [15].

\section{Lung function tests}

All subjects underwent body plethysmography (Bodystar FG 90; Fenyves and Gut, Basel, Switzerland), transfer factor assessment for the lung with the single breathholding method (transfer factor of the lung for carbon 
monoxide $(T \mathrm{~L}, \mathrm{CO}))$, including membrane $(\mathrm{Dm})$ and capillary (Vc) components (T.T, Autolink; Morgan, Andover, MA, USA) and blood gas analysis (BG3, Instrumentation Laboratory, Paderno Dugnano, Italy).

\section{Assessment of symptoms}

The occurrence of symptoms disturbing sleep and affecting day-time activities was ascertained by the rheumatologist (P. Sarzi Puttini) during the patients' medical history interview.

\section{Statistical analysis}

Data are reported as mean \pm SD. Statistical analysis of the anthropometric data, polysomnographic recordings and lung function tests was performed using the unpaired Student's t-test.

Pearson's Chi-squared test was used for other comparisons of means and proportions. Mann-Whitney U-test, the Spearman Rank correlation and linear regression analysis were used where appropriate. The level of significance was $\mathrm{p}<0.05$. All statistical analyses were performed using the statistical package SPSS V.6.1 (SPSS Inc., Chicago, IL, USA).

\section{Results}

Table 1 shows anthropometric data, pulmonary function tests and blood gases of FMS patients and the control group. Lung volumes did not differ between the two groups, but the transfer factor ( $T \mathrm{~L}, \mathrm{CO})$, transfer coefficient and diffusing capacity of the alveolar membrane (Dm) were significantly reduced in FMS group $(\mathrm{p}<0.01)$. As shown in table 2 , the most common complaints of FMS patients were nocturnal awakening $(100 \%)$, chronically poor sleep and fatigue $(90 \%)$, morning headache and a

Table 3. - Polysomnographic data in fibromyalgia syndrome (FMS) patients and control

\begin{tabular}{lccc}
\hline & FMS & $\begin{array}{c}\text { Control } \\
\text { subjects }\end{array}$ & p-value \\
\hline Sleep time min & $303 \pm 80$ & $398 \pm 33$ & 0.001 \\
Stage 1 \% sleep time & $21 \pm 6$ & $11 \pm 4$ & 0.001 \\
Stage 2 \% sleep time & $34 \pm 8$ & $38 \pm 8$ & $\mathrm{NS}$ \\
Stage 3 \% sleep time & $7 \pm 5$ & $12 \pm 3$ & 0.01 \\
Stage 4 \% sleep time & $1 \pm 1$ & $8 \pm 4$ & 0.0001 \\
REM \% sleep time & $17 \pm 9$ & $16 \pm 5$ & $\mathrm{NS}$ \\
Sleep efficiency \% & $79 \pm 10$ & $89 \pm 6$ & 0.01 \\
Sa,O $\%$ average dur- & $94.4 \pm 1.9$ & $95.3 \pm 1.5$ & $\mathrm{NS}$ \\
ing sleep & & & \\
Sa,O $\%$ nadir during & $85.4 \pm 8.7$ & $89.6 \pm 2.2$ & $\mathrm{NS}$ \\
sleep & & & \\
DEF events $\cdot \mathrm{h}^{-1}$ & $8.6 \pm 5$ & $3.3 \pm 3.2$ & 0.001 \\
DEF total n & $37 \pm 20$ & $16 \pm 10$ & 0.001 \\
Total DEF duration s & $517 \pm 574$ & $161 \pm 163$ & 0.05 \\
Mean duration of & $10 \pm 0.7$ & $5 \pm 0.4$ & 0.01 \\
DEF s & & & \\
RDI events $\cdot \mathrm{h}^{-1}$ & $5.1 \pm 3.5$ & $3.2 \pm 1.6$ & $\mathrm{NS}$ \\
PB \% sleep time & $15 \pm 8$ & $1 \pm 2$ & 0.0001 \\
Arousal index $\mathrm{n} \cdot \mathrm{h}^{-1}$ & $8.4 \pm 3.5$ & $4.0 \pm 1.4$ & 0.001 \\
\hline Data presented as & & & \\
\hline
\end{tabular}

Data presented as mean \pm SD. DEF: desaturation event frequency; RDI: respiratory disturbance index; PB: periodic breathing; REM: rapid eye movement; $\mathrm{Sa}_{\mathrm{a}} \mathrm{O}_{2}$ : arterial oxygen saturation. sensation of waking-up unrefreshed (82\%), and daytime hypersomnolence $(59 \%)$ ( $\mathrm{p}<0.01$ versus controls).

PSG recordings (table 3 ) showed that FMS patients had lower sleep efficiency than controls $(\mathrm{p}<0.01)$, and twice as many arousals per hour of sleep $(p<0.001)$. The percentage of stage 1 sleep was markedly increased in FMS patients, causing a reduction of slow wave sleep $(p<0.01)$, but not of the stage 2 and rapid eye movement (REM) phase sleep. Sporadic alpha intrusion during delta sleep was identified in 5/17 patients (29\%) and in one control subject $(6 \%)$, but its occurrence was too limited to allow any sort of analysis.

The total number, the number $\cdot \mathrm{h}^{-1}$ and duration of DEF during sleep were higher in patients $(\mathrm{p}=0.001 ; 0.01 ; 0.05$, respectively), than in control subjects. There was no difference in RDI, $\mathrm{Sa}_{\mathrm{a}} \mathrm{O}_{2}$ average and nadir during sleep between FMS and control subjects (table 3 ).

$\mathrm{PB}$ was observed in $15 / 17$ patients $(88 \%)$ but only in two of the control group (12\%) in both of whom it was limited to sleep onset. The usual length of apnoeic or hypopnoeic episodes during PB was $<10 \mathrm{~s}$; therefore the RDI and $\mathrm{Sa}, \mathrm{O}_{2}$ average during sleep did not differ between the two groups. Nevertheless, PB was present for a mean $15 \%$ of the night in FMS patients, mainly occurring during light stages of REM sleep. The pattern of PB showed a crescendo-decrescendo of tidal volume, interrupted by the breathing pauses, in 11 patients (fig. 1), while in the four remaining patients the end of breathing pause was followed by an immediate surge of ventilation, with a pattern more similar to a cluster (fig. 2). A comparison between patients with or without PB was not possible, since only two patients had no PB at all. The best correlations between $\mathrm{PB}$ and functional data were obtained with TL,CO, DEF and $\mathrm{Pa}_{2} \mathrm{CO}_{2}$ (table 4).

Patients complaining of daytime hypersomnolence had a higher number of TP, about double the number of arousals per hour and a lower sleep efficiency than patients who did not report this symptom. TL,CO was more impaired and the occurrence of PB higher (table 5) in patients with daytime hypersomnolence.

\section{Discussion}

\section{Sleep architecture and hypersomnolence}

FMS is a disease with a higher female prevalence, causing poor sleep in $60-90 \%$ of subjects $[1,3-5]$. It is not surprising that the current case series of consecutive FMS patients selected a predominantly female population who complained of symptoms such as nocturnal awakening, poor sleep quality, fatigue, morning headache and wakingup unrefreshed significantly more often than the control group. However, the severity of these symptoms is not supported by any finding of dramatic alterations in PSG. The amount of stage 1 sleep was increased in FMS patients to a mean $21 \%$ of sleep time, but only slow wave sleep was reduced. Although MoldofsKi et al [6] showed that a slow wave sleep deprivation could exacerbate pain and asthenia during the daytime, this can hardly explain hypersomnolence. The amount of both stage 2 and REM phases was not different from control subjects, thus excluding REM deprivation as a possible cause of excessive anxiety or psychological disorders which could lead to an overestimation of symptoms. The number of arousals was about twice that in control subjects, but still lower than 10 


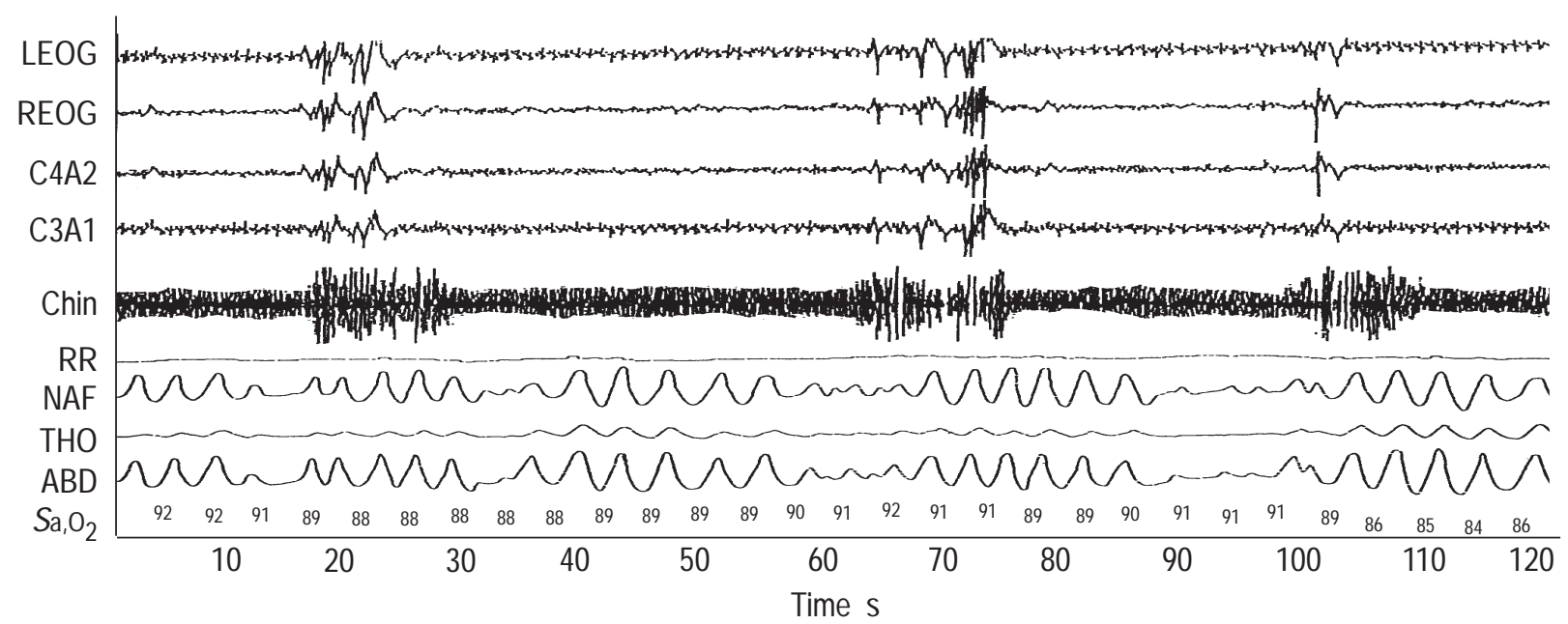

Fig. 1. - Polysomnographic recordings of periodic breathing "crescendo-decrescendo" in patients affected by fibromyalgia syndrome. All records show, from the top down, left and right electrooculogram (LEOG, REOG), electroencephalogram (EEG: C4A2, C3A1 of the 10-20 international electrode placement system), submental electromyogram (Chin), R-R time interval between two consecutive R waves of the EEG (RR), naso-oral airflow (NAF), respiratory thoracic effort (THO), respiratory abdominal effort (ABD), percentage oxygen saturation $\left(\mathrm{Sa}_{\mathrm{a}} \mathrm{O}_{2}\right)$.

episodes $\cdot \mathrm{h}^{-1}$, a figure which is rarely associated with hypersomnolence and far lower than that reported in other diseases causing poor sleep quality and hypersomnolence, (i.e. obstructive sleep apnoea syndrome (OSAS)). The analysis of arousal was performed according to ASDA criteria [14], which include both EEG arousals and movement arousals lasting $>3 \mathrm{~s}$. The alpha-delta intrusion, reported in a previous study as a possible factor disrupting sleep [9], occurred sporadically in the current series of patients; therefore, a paramount role in the pathogenesis of hypersomnolence cannot be alleged on the basis of these data. The presence of another sleep related respiratory disorder, namely OSAS, was not detected in this population of nonobese FMS patients, although more than half were snorers, a result in accordance with MoLONY et al [10]. Also, the possibility of an upper airway resistance syndrome seems to be excluded by a number of arousals lower than $10 \mathrm{~h}^{-1}$.
It is thus possible that the usual criteria applied to other patients (i.e. OSAS patients) cannot be used in FMS patients. The shorter interval from the onset of disease could possibly play a major role, since it was $<5$ yrs as a mean in the FMS patients, whilst OSAS patients usually have a long history of snoring progressing only slowly (often over decades) to OSAS [16]. The high female prevalence could play a role as well, since females tend to over report symptoms of sleep disturbance [17].

\section{Periodic breathing and diffusion abnormalities}

An intriguing finding of this study was the oscillation in ventilation during sleep observed in 15/17 FMS patients, structured in a typical periodic breathing pattern occurring mainly during Phase 1 . This did not affect the RDI because most apnoeic and hypopnoeic episodes lasted $<10 \mathrm{~s}$. On the contrary, the DEF was increased, despite the high basal $\mathrm{S} \mathrm{a}, \mathrm{O}_{2}$ values, and the short length of apnoeas/hypopnoeas.

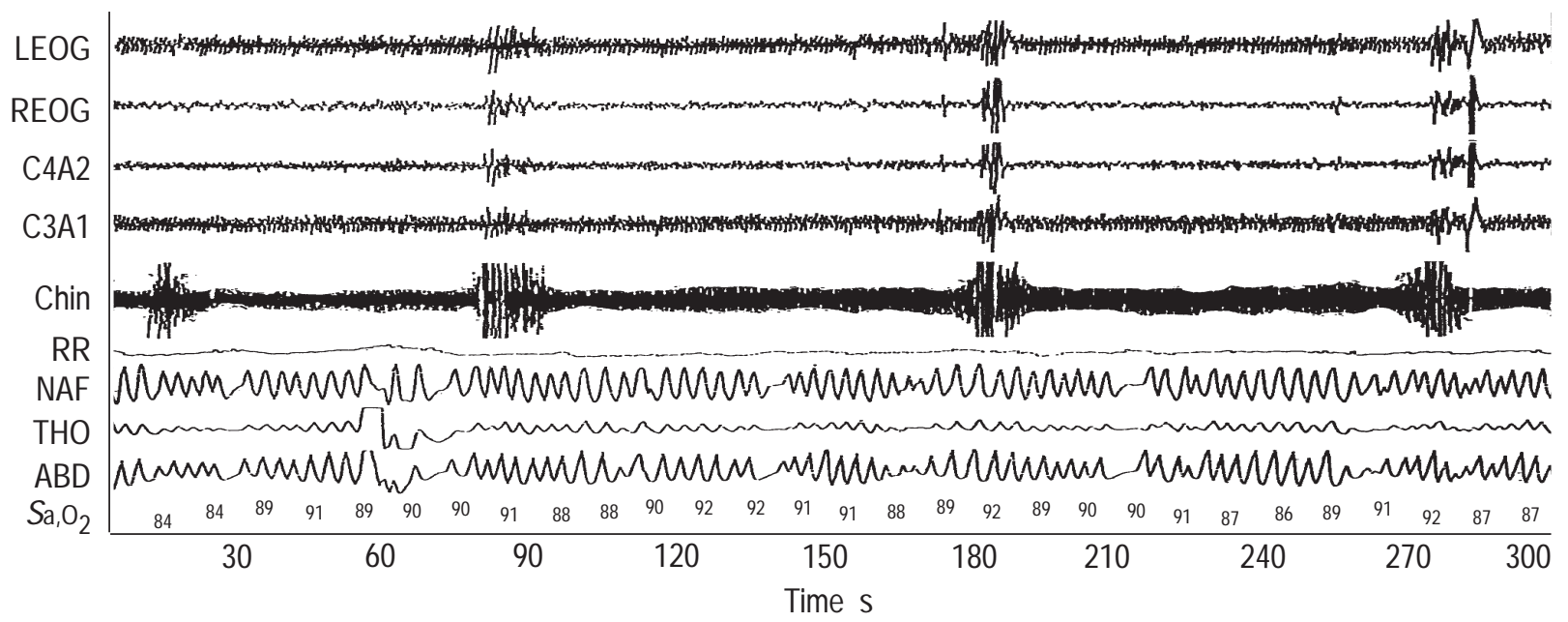

Fig. 2. - Polysomnographic recordings of periodic breathing "cluster" in patients affected by fibromyalgia syndrome. All records show, from the top down, left and right electro-oculogram (LEOG; REOG), electroencephalogram (EEG: C4A2, C3A1 of the 10-20 international electrode placement system), submental electromyogram (Chin), R-R time interval between two consecutive R waves of the EEG (RR), naso-oral airflow (NAF), respiratory thoracic effort (THO), respiratory abdominal effort (ABD), percentage oxygen saturation $\left(\mathrm{S}_{\mathrm{a}}, \mathrm{O}_{2}\right)$. 
Table 4. - Spearman rank correlation between the occurrence of periodic breathing and sleep, laboratory and functional data

\begin{tabular}{lcc}
\hline$\%$ Periodic breathing versus & $\mathrm{r}$ & $\mathrm{p}$-value \\
\hline TL,CO mmol $\cdot \mathrm{min}^{-1} \cdot \mathrm{kPa}^{-1}$ & -0.62 & 0.01 \\
Daytime $P \mathrm{a}, \mathrm{CO}_{2} \mathrm{kPa}$ & -0.50 & 0.05 \\
DEF total number & 0.76 & 0.001 \\
DEF $\mathrm{h}^{-1}$ & 0.62 & 0.01 \\
\hline
\end{tabular}

$T \mathrm{~L}, \mathrm{CO}$ : transfer factor of the lung for carbon monoxide; $\mathrm{Pa}_{\mathrm{a}, \mathrm{CO}_{2} \text { : }}$ : arterial blood carbon dioxide pressure; DEF: desaturation event frequency.

The occurrence of PB for a mean $15 \%$ of sleep time could play an important role in the "poor sleep" complaints of these patients. To the authors' knowledge there have been no previous reports of this respiratory pattern during sleep in FMS patients. It is well known that PB may be related to an unstable operation of the control system of ventilation, elicited by the transition from wakefulness to sleep, which can occur even in normal subjects for a limited time, as was the case in two of the control subjects. When sleep becomes more consolidated PB usually disappears [18]. Pain can reduce sleep efficiency, causing more arousals and more stage 1 sleep, and increasing the chances for PB to appear. However, the occurrence of PB in the patients $(15 / 17$, versus $2 / 17$ control subjects) is too high to be explained only on this basis. The absence of neurological diseases or cardiac failure exclude the two most common causes of PB. Upper airway reflexes could possibly play a role at least in the maintenance of $\mathrm{PB}$, since many patients were snorers and the oscillations of upper airway resistances can produce a fluctuating limitation of ventilation contributing to PB [19]. However, $\mathrm{PB}$ also occurred in nonsnorers and snoring was not necessarily present during PB in snorers. A reduction in lung volume can affect upper airway cross-sectional area [19], but again this is not the case of these patients (table 1).

The second unexpected finding of this study, the TL,CO reduction in FMS patients, may throw some light on the pathogenesis of PB. Again, to the authors' knowledge, there are no previous reports of this finding in FMS patients, probably because this index is not routinely measured, since pulmonary function and blood gases are usually normal, as was the case in these patients. When TL,CO is

Table 5. - Comparison of laboratory, functional and sleep related data in 17 fibromyalgia syndrome (FMS) patients stratified according to the reported complaint of hypersomnolence

\begin{tabular}{lccc}
\hline & \multicolumn{2}{c}{ Hypersomnolence } & \\
\cline { 2 - 3 } & \multicolumn{1}{c}{ Yes } & No & p-value \\
\hline Patients n & 10 & 7 & \\
Tender points n & $15 \pm 2$ & $12 \pm 1$ & 0.01 \\
Arousal index events $\cdot \mathrm{h}^{-1}$ & $10 \pm 3$ & $6 \pm 2$ & 0.01 \\
Sleep efficiency \% & $79 \pm 10$ & $89 \pm 6$ & 0.05 \\
TL,CO sb mmol $\mathrm{min}^{-1} \cdot \mathrm{kPa}^{-1}$ & $16 \pm 3$ & $19 \pm 2$ & 0.05 \\
PB \% sleep time & $18 \pm 7$ & $11 \pm 7$ & 0.05 \\
\hline
\end{tabular}

The parameters reported are only those which showed a statistically significant difference between groups. Data are mean \pm SD. TL,CO sb: transfer factor of the lung for carbon monoxide single breath holding method; PB: periodic breathing. reduced, a normal oxygen tension in arterial blood $\left(\mathrm{Pa}_{\mathrm{a}} \mathrm{O}_{2}\right)$ is maintained only by hyperventilation which causes a $P \mathrm{a}, \mathrm{CO}_{2}$ decrease. Comparing FMS patients showing PB with control subjects, the $P_{a}, C_{2}$ was slightly lower but the difference did not reach a statistical significance $(4.8 \pm 0.3$ versus $5.3 \pm 0.7 \mathrm{kPa}, \mathrm{p}=0.06$ ).

A comparison between patients with and without PB was not possible since only two patients did not show this breathing pattern. A negative correlation was found between the occurrence of $\mathrm{PB}$ and $\mathrm{Pa}_{2} \mathrm{CO}_{2}$ (the lower the $\mathrm{Pa}_{\mathrm{a}} \mathrm{CO}_{2}$, the higher the $\mathrm{PB}$ percentage), and between $\mathrm{PB}$ and TL,CO.

The lower TL,CO can hardly be the only cause of PB occurrence in the patients since $P \mathrm{a}, \mathrm{O}_{2}$ during daytime is not different between patients and control subjects, but the slight hyperventilation caused by mechanoreceptor stimulation and a $P \mathrm{a}_{1} \mathrm{CO}_{2}$ nearer to the apnoea threshold could facilitate the respiratory control instability.

No explanation for the lower TL,CO in FMS patients is apparent: pulmonary function tests were normal; haemoglobin levels were similar to normal subjects (which excludes the possibility of occult bleeding due to the frequent use of anti-inflammatory drugs); all patients were nonsmokers; and when the measurement was normalized by "CO back-tension" (carboxyhaemoglobin ) the data did not change. Chest radiographs seem to exclude an interstitial reinforcement, although this does not rule out the disease's having a very early pulmonary involvement.

The overlap of relative hypocapnia, hyperventilation and ventilatory instability at sleep onset and during the lighter stages of sleep (possibly enhanced by pain related sleep disruption) could perhaps explain the occurrence of PB in FMS subjects. The similarities with high altitude PB, short apnoeas/hypopnoeas, "poor sleep" complaints, increased percentage of phase 1 sleep [18], further support the hypothesis of a hypoxic-hypocapnic mechanism.

\section{Limitations of the study}

Both the reduction in gas transfer and the occurrence of PB were unexpected findings, therefore the possibility of a subtle diffuse lung disease or pulmonary vascular disturbance cannot be excluded. High resolution computed tomography scans or pulmonary haemodynamics are obviously not included in the routine assessment of these patients who are managed by rheumatologists as out-patients.

Healthy subjects were selected as a control group. Although they were well-matched with the patients in terms of age, sex, BMI, and respiratory function, the results could have been different had matched control subjects from a clinical population been chosen. The prevalence of PB would probably not be affected, but a higher percentage of light sleep stages could be hypothesized in patients affected by a disease causing a chronic pain.

The use of benzodiazepines at low dosage in two of the patients was stopped two weeks before the study. Both patients did not report a change in subjective quality of sleep and it seems difficult to explain any of the results as a rebound effect of the withdrawal. 


\section{Conclusions}

In conclusion, the data indicate that the nonrestorative sleep of fibromalgia syndrome patients is not linked to a marked sleep disruption. Patients affected by fibromalgia syndrome may be more easily arousable, have less slow wave sleep, a condition possibly exacerbating pain and in turn inducing a progressively poorer sleep, but have a normal percentage of phase 2 and rapid eye movement sleep. The unexpected occurrence of periodic breathing in $15 / 17$ patients, linked to a reduction of transfer factors of the lung for carbon monoxide, could play a major role in the symptoms of poor sleep of these patients. An investigation into the causes of this reduction in transfer factors of the lung for carbon monoxide and of the effects of periodic breathing prevention on day-time symptoms of fibromyalgia syndrome patients seems warranted.

\section{References}

1. Jacobsen S, Petersen IS, Danneskiold-Samsoe B. Clinical features in patients with chronic muscle pain with special reference to fibromyalgia. Scand J Rheumatol 1993; 22: 69-76.

2. Wolf F, Smythe HA, Yunus MB, et al. The American College of Rheumatology 1990 criteria for the classification of fibromyalgia: report of the multicenter criteria committee. Arthritis Rheum 1990; 33: 160-172.

3. Mufson M, Regenstein QR. The spectrum of fibromyalgia disorders. Arthritis Rheum 1993; 36: 647-650.

4. Drewes AM, Jennum P, Andersen A, Siol A, Nilesen KD. Self-reported sleep disturbances and daytime complaints in women with fibromyalgia and rheumatoid arthritis. $J$ Musculoskeletal Pain 1994; 2: 15-31.

5. Carette S, Oakson G, Guimont C, Steriade M. Sleep electroencephalography and the clinical response to amitriptyline in patients with fibromyalgia. Arthritis Rheum 1995; 38: 1211-1217.

6. Moldofsky H, Scarisbrick P. Induction of neurasthenic musculoskeletal pain syndrome by selective sleep stage deprivation. Psychosom Med 1976; 38: 35-44.

7. Moldofsky H, Scarisbrick P, England R, Smythe H. Musculoskeletal symptoms and non-REM sleep disturbance in patients with "fibrositis syndrome" and healthy subjects. Psychosom Med 1975; 37: 341-351.

8. Branco J, Atalaia A, Paiva T. Sleep cycles and Alphadelta sleep in fibromyalgia syndrome. J Rheumatol 1994; 21: 1113-1117.

9. Drewes AM, Nielsen KD, Jennum P, Andreasen A. Alpha intrusion in fibromyalgia. J Musculoskeletal Pain 1993; 1: 223-228.

10. Schealer W, Kubicki S, Marquardt J, et al. The alphasleep pattern: quantitative analysis and functional aspects. In: Koella WP, Obal F, Schultz H, Visser P, eds. Sleep 1986. Stuttgart, Fischer, 1988; 45-53.

11. Molony RR, MacPeek DM, Schiffmann PL, et al. Sleep, sleep apnea and the fibromyalgia syndrome. J Rheumatol 1986; 13: 797-800.

12. Lario BA, Teran J, Alonso JL, Alegre J, Arroyo I, Viejo JL. Lack of association between fibromyalgia and sleep apnoea syndrome. Ann Rheum Dis 1992; 51: 108-111.

13. Rechtshaffen A, Kales A, eds. A manual of standardized terminology, techniques and scoring system for sleep stages of human subjects. Government Printing Office, Washington D.C, 1968. (NIH publication No. 204).

14. Bonnet M, Carley D, Carskadon M, et al. EEG Arousals: scoring rules and examples. A preliminary report from the sleep disorders atlas task force of the American Sleep Disorders Association. Sleep 1992; 15: 173-184.

15. Guilleminault C. Obstructive sleep apnoea: the clinical syndrome and historical perspective. Med Clin North Am 1985; 69: 1187-1203.

16. Lugaresi E, Cirignotta F, Geraldi R, Montagna P. Snoring and sleep apnoea: natural history of heavy snorers disease. In: Guilleminault C, Partinen M, eds. Obstructive Sleep Apnoea Syndrome. Raven Press, New York, 1990; pp. 25-36.

17. Newman AB, Enright PL, Manolio TA, Haponik EF, Wahl PW, on behalf of the Cardiovascular Research Group. Sleep disturbance, psychosocial correlates, and cardiovascular disease in 5201 older adults: the cardiovascular health study. J Am Geriatr Soc 1997; 45: 1-7.

18. Phillipson EA. Control of breathing during sleep. Am Rev Respir Dis 1978; 118: 909-939.

19. De Backer WA. Central sleep apnoea, pathogenesis and treatment: an overview and perspective. Eur Respir $J$ 1995; 8: 1372-1383. 